\title{
The effect of the platelet-rich plasma on osteogenic potential of the periosteum in an animal bone defect model
}

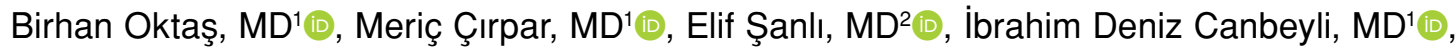 \\ Önder Bozdoğan, $\mathrm{MD}^{3}$ (D) \\ 1Department of Orthopedics and Traumatology, Kırıkkale University Faculty of Medicine, Kırıkkale, Turkey \\ ${ }^{2}$ Department of Plastic, Reconstructive and Esthetic Surgery, Kırıkkale University Faculty of Medicine, Kırıkkale, Turkey \\ ${ }^{3}$ Department of Pathology, Ministery of Health Gülhane Training and Research Hospital, Ankara, Turkey
}

Periosteum is a major source of mesenchymal stem cells which are essential during fracture healing. Cambium layer of periosteum includes osteoprogenitor cells which can differentiate into either osteoblasts or chondroblasts under proper induction..$^{[1]}$ Its osteogenic potential has been also proved by many animal and clinical studies even as a free periosteal graft. ${ }^{[2-4]}$ In many other studies, periosteum has been shown to be a vital tissue for bone regeneration in the existence of growth factors such as insulin-like growth factor (IGF), fibroblast growth factor (FGF), transforming growth factor-beta (TGF- $\beta$ ), vascular endothelial growth factor (VEGF), and bone morphogenic protein (BMP). ${ }^{[1,3,5]}$ Recently, repositioning or distraction of periosteum, application of platelet-rich plasma (PRP), hyaluronic acid (HA), and BMP are reported to be used to increase periosteal osteogenesis. ${ }^{[6-8]}$

Received: April 23, 2021

Accepted: July 19, 2021

Published online: November 19, 2021

Correspondence: Birhan Oktaş, MD. Kırıkkale Üniversitesi Tıp

Fakültesi Ortopedi ve Travmatoloji Anabilim Dalı,

71450 Yahşihan, Kırıkkale, Türkiye.

E-mail: birhanoktas@kku.edu.tr

Doi: $10.52312 /$ jdrs.2021.199

Citation: Oktaș B, Çıpar M, Sanlı E, Canbeyli ID, Bozdoğan Ö. The effect of the platelet-rich plasma on osteogenic potential of the periosteum in an animal bone defect model. Jt Dis Relat Surg 2021;32(3):668-675.

(O2021 All right reserved by the Turkish Joint Diseases Foundation

This is an open access article under the terms of the Creative Commons Attribution-NonCommercial License, which permits use, distribution and reproduction in any medium, provided the original work is properly cited and is not used for commercial purposes (http://creativecommons.org/licenses/by-nc/4.0/).

\section{ABSTRACT}

Objectives: This study aims to investigate whether plasma-rich plasma (PRP) enhances the osteogenic potential of periosteal grafts used to repair bone defects and maintains both histologically and biomechanically more durable bone tissue.

Materials and methods: A standard bone defect was formed to the left femurs of 54 Sprague-Dawley rats and three groups were formed. In the first group $(n=18)$, no periosteal repair was done for bone defect. In the second group $(n=18)$, periosteal graft tissue was sutured to cover the defect entirely. In the third group $(n=18)$, before periosteal repair, a $1 \mathrm{~mL}$ of PRP fibrin was applied into the bone defect. All femoral specimens were compared histologically at four and six weeks and biomechanically by three-point bending test at six weeks after treatment.

Results: In the PRP applied group, healing of the bone defect at four weeks was significantly better than the other groups in terms of histological new bone formation $(\mathrm{p}<0.05)$. At six weeks, new bone formation in both of the periosteum preserved groups was superior to the first group ( $\mathrm{p}<0.05$, for both). There was no statistically significant difference between the second and third groups at the end of the sixth week in the biomechanical analysis, although both groups were significantly stronger than the first group $(\mathrm{p}<0.05)$.

Conclusion: Stimulation of the periosteum with PRP application causes early osteogenic differentiation of precursor cells. Although, at biomechanical basis, PRP application does not create any significant difference, in the recovery of the bone defects at very early period, application of PRP may play a role to accelerate fracture healing and to decrease nonunions.

Keywords: Fracture healing, osteogenesis, periosteum, platelet-rich plasma.

The PRP is a product of centrifuged whole blood with its high (3 to 8 times) platelet count. Many growth factors including platelet-derived growth factor (PDGF), IGF-1 and IGF-2, TGF- $\beta$, VEGF, and FGF have been studied after PRP applications at the site of injections. ${ }^{[9,10]}$ The degradation of platelets are the main sources of these growth and differentiation 
factors. This property of PRP has caused its wide acceptance for the treatment of much orthopedic pathology such as tendinopathy, chondropathy, osteoarthritis, muscular injuries, fractures, and even nonunions. ${ }^{[11-13]}$

There is a limited number of studies focusing on PRP-induced periosteal osteogenesis and most of them are in the fields of dental or craniofacial surgery. ${ }^{[7,14,15]}$ Bone regeneration capacity of periosteal tissue under the influence of growth factors obtained from PRP has not been examined in bone defects in detail. In the present study we hypothesized that periosteum might have a greater capacity for osteogenesis when processed with PRP and would result in a histologically and biomechanically enhanced new bone formation in a shorter time period. We, therefore, aimed to histologically and biomechanically evaluate the effect of PRP-based growth factors on periosteal osteogenesis in an animal bone defect model.

\section{MATERIALS AND METHODS}

\section{Study design and study samples}

Fifty-six male Sprague-Dawley rats were obtained from a national animal supplier laboratory. All rats were weighted between 300 and $400 \mathrm{~g}$ and they were 10 weeks old. Animals were observed in an animal research laboratory for one week for any disease or malformation. During all procedures, a 12-h light-dark regimen at $21^{\circ} \mathrm{C}$ was provided and rats were able to reach freely to food and water ad libitum. The study was approved by the Kirıkkale University Animal Researchs Ethics Committee (No. 0016, Date: 27.12.2013). All animal cares and experiments were conducted in accordance with the ETS-123 and European Convention for the Protection of Vertebrate Animals Used for Experimental and Other Scientific Purposes. The rats were divided randomly into three groups of 18 animals each. In Group $1(n=18)$, elevated periosteal tissue previous to formation of bone defect was totally removed. In Group $2(n=18)$, periosteum was repaired with $4 / 0$ propylene suture after defect formation. In Group $3(n=18)$, before repair of periosteum, $1 \mathrm{~mL}$ of PRP fibrin was applied subperiosteally. Two rats were reserved for PRP preparation.

\section{Preparation of platelet-rich plasma}

Two animals were anesthetized and prepared for PRP production as described previously by Çirci et al. ${ }^{[9]}$ After sanitization of their chest wall, $10 \mathrm{~mL}$ of blood was drawn from each rat via an intracardiac puncture. All blood was drawn into a PRP preparation kit (Harvest ${ }^{\circledR}$ APC-20 Procedure Pack; Harvest Technologies Corp., MA, USA), which contains $2 \mathrm{~mL}$ of citrate phosphate dextrose solution. After centrifugation of sample $(1,500 \mathrm{rpm} / 10 \mathrm{~min}), 2 \mathrm{~mL}$ of PRP was obtained. Totally, $10 \%$ sodium chloride solution was added and a second centrifugation $(1,500 \mathrm{rpm} / 5 \mathrm{~min})$ was done to obtain non-liquid platelet-rich fibrin gel (Figure 1).

\section{Surgical procedure}

$\begin{array}{ccc}\text { After } & \text { ketamine } & \text { hydrochloride } \\ \text { [50 } \mathrm{mg} / \mathrm{kg} \text {-intraperitonealy } & \text { [IP])-xylazin }\end{array}$
hydrochloride $(7 \mathrm{mg} / \mathrm{kg}$ IP) anesthesia, all rats preoperatively received cefazolin sodium (20 $\mathrm{mg} / \mathrm{kg})$ intramuscularly for antibiotic prophylaxis. Left thigh of all rats were shaved and prepared for surgery with betadine solution. Under sterile conditions, vastus lateralis muscle was exposed through a lateral longitudinal incision and retracted anteriorly with blunt dissection. Diaphyses of femurs were reached and periosteal tissue was elevated in rectangular shape protecting one side as a hinge. In the mid-diaphyses of all femurs, a $3.2 \mathrm{~mm}$ standard radial drilling was applied on the periosteum elevated area to create a non-critical sized bone defect as described in previous studies (Figure 2). ${ }^{[16]}$ In periosteum intact groups (Group 2 and Group 3), periosteum was repaired with 4/0 Vicryl to cover the defect area (Figure 3). All muscle layers and skin were closed with 4/0 Vicryl suture properly. The rats were allowed in free action without any nutritional restriction.

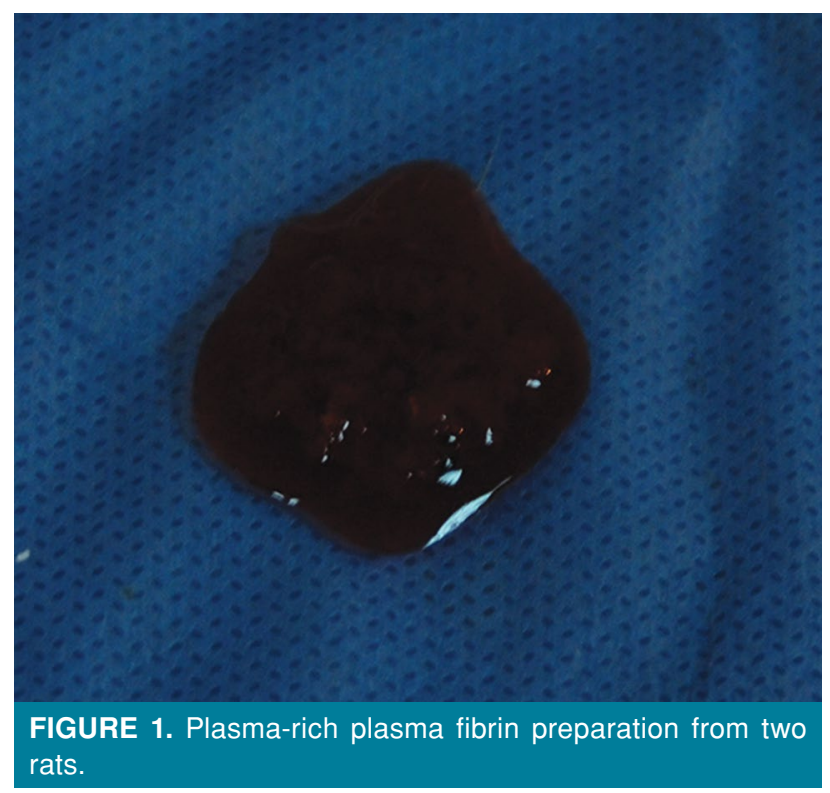




\section{Histological examination}

For histological evaluation, six rats from each group at the end of the fourth week and sixth week were selected randomly and sacrificed under general anesthesia with pentobarbitone (>200 mg/kg). The whole femurs were extirpated by disarticulation at the hip and knee. Soft tissues were dissected to expose the femurs. All femurs were numbered randomly. The specimen was, then, fixed in $10 \%$ buffered formalin and treated with decalcification solution. After $24 \mathrm{~h}$, specimens were cut in $5 \mu \mathrm{m}$ in thickness and stained with hematoxylin-eosin and trichrome staining. Histopathological examination was performed by a blind pathologist who was blind to the numbered specimens of each group. All specimens were scored according to the percentile-based scales. Bone defect was divided into 10 areas and newly formed bone was measured at $10 \times$ magnification. All areas with new bone formation were added and calculated as percentile of whole defect, as described previously. ${ }^{[17]}$ Total scores were noted for each specimen and average scores were calculated. In addition, bone marrow formation was evaluated and presented in numbers from 1 to 0 to explain existence.
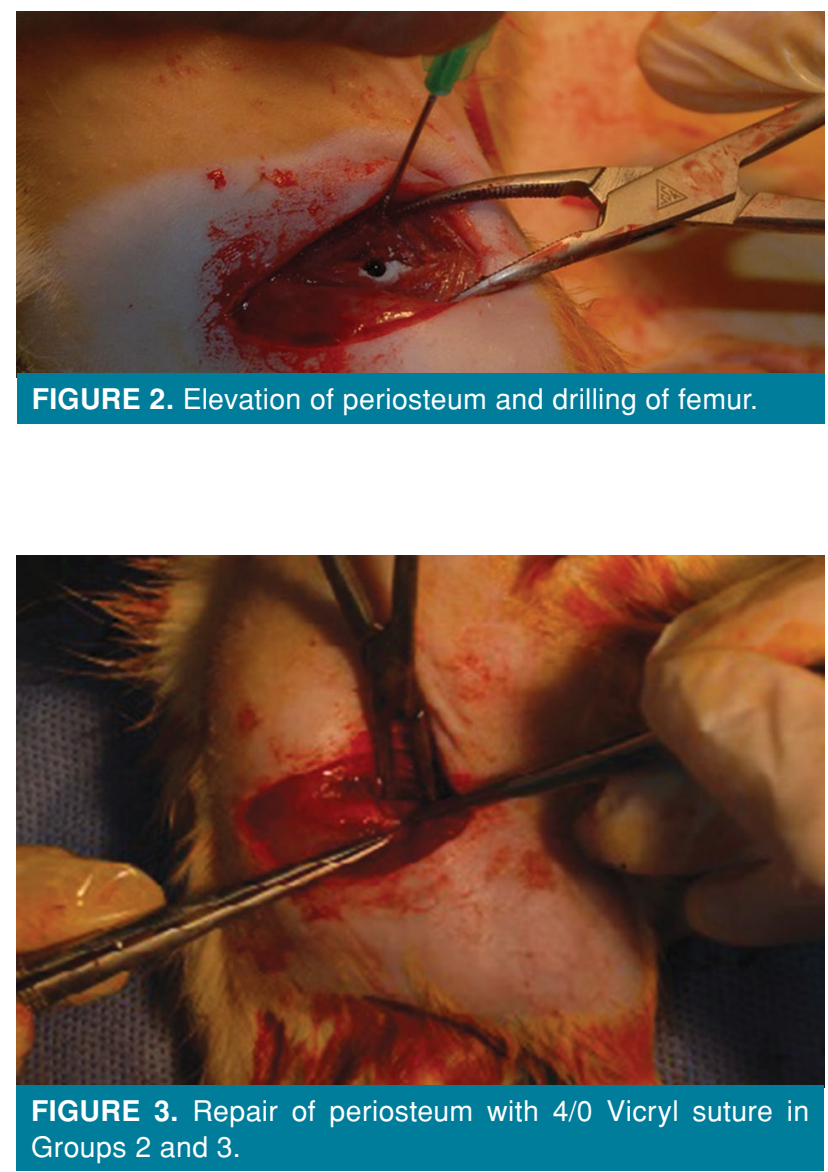

\section{Biomechanical testing}

At the end of the sixth week, the remaining rats from each group $(n=6)$ were sacrificed and left femurs were obtained from each rat. A blind examiner tested femurs with a three-point bending device immediately after scarification, as described previously. ${ }^{[18]}$ A three-point bending device with a load cell at the moving arm was used (Alşa Lab Cihazları San. ve Tic. Ltd. Şti, Istanbul, Turkey) (Figure 4). Loading was continued at a constant deflection speed of $1 \mathrm{~mm} / \mathrm{min}$ until bone samples failed. Load-to-failure curves were obtained and maximum load-to-failure for each femur was recorded by an analysis program (TestLAB Basic- Testbox1001Teknik Destek Grubu, Ankara, Turkey) (Figure 5). Intergroup variability was tested and all results were evaluated by another examiner.

\section{Statistical analysis}

Statistical analysis was performed using the IBM SPSS version 20.0 software (IBM Corp., Armonk, NY, USA). Descriptive data were expressed in mean \pm standard deviation (SD) or number and frequency, where applicable. The Pearson chi-square test was

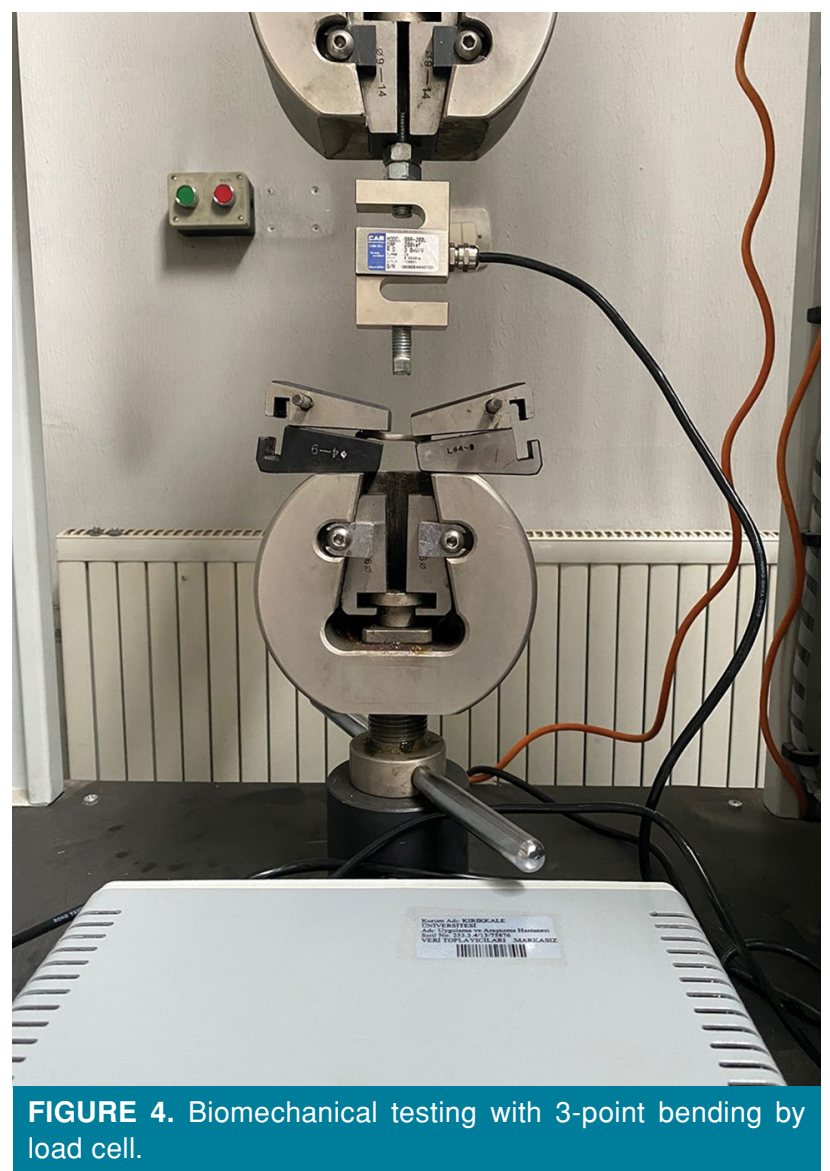




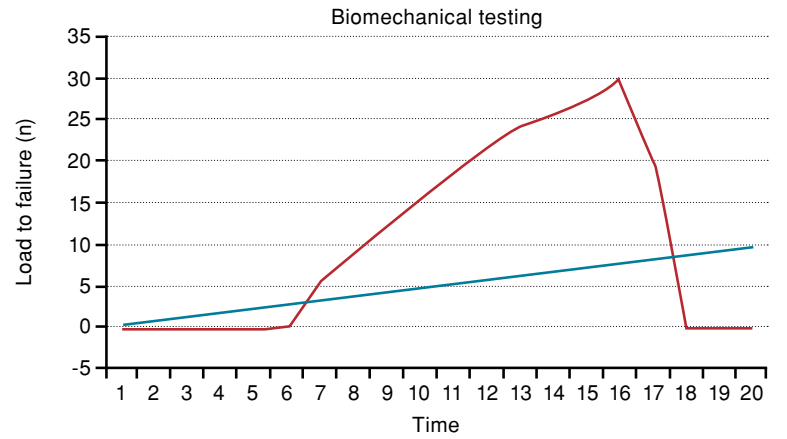

FIGURE 5. Strain-force versus time curve obtained for each specimen. Depletion point of curve accepted as minimum load-to-failure.

used to evaluate differences in categorical variables among the groups. To evaluate differences in the parametric variables among the groups, one-way analysis of variance (ANOVA) test was used. In the post-hoc comparisons, the Tukey multiple comparison test was used. The paired samples t-test and Wilcoxon signed-rank test were carried out to determine the significant difference between the repeated measures for each group $(\mathrm{p}<0.05)$. Parametric tests were used for bone marrow formation, while the Mann-Whitney $\mathrm{U}$ test was used to compare new bone formation. A $p$ value of $<0.05$ was considered statistically significant.

\section{RESULTS}

In this study, we evaluated the effect of PRP on periosteal osteogenesis histologically at four and six weeks and biomechanically at six weeks after bone defect formation. Descriptive data of the groups and both histological and biomechanical analysis results are summarized in Table I. In tissue samples at four and six weeks, Group 3 (periosteum repaired and

\begin{tabular}{|c|c|c|c|c|c|}
\hline \multicolumn{6}{|c|}{$\begin{array}{c}\text { TABLE I } \\
\text { oth histologi }\end{array}$} \\
\hline \multirow[b]{2}{*}{ Variables } & Group 1 & Group 2 & Group 3 & \multirow[b]{2}{*}{$\mathrm{F} / \chi^{2}$} & \multirow[b]{2}{*}{$p$} \\
\hline & Mean $\pm S D$ & Mean $\pm S D$ & Mean $\pm S D$ & & \\
\hline Load-to-failure (Newton) & $9.5 \pm 1.7$ & $13.1 \pm 1.5$ & $13.1 \pm 1.6$ & 10.351 & 0.002 \\
\hline New bone formation at 4 week (dd\%) & $7.0 \pm 8.3$ & $12.0 \pm 11.0$ & $33.3 \pm 15.1$ & 7.527 & 0.007 \\
\hline New bone formation at 6 week (dd\%) & $6.0 \pm 4.2$ & $32.0 \pm 16.4$ & $56.7 \pm 12.1$ & 24.195 & 0.000 \\
\hline Bone marrow formation at 4 week & $0.0 \pm 0.0$ & $0.4 \pm 0.6$ & $0.7 \pm 0.5$ & 3.122 & 0.078 \\
\hline Bone marrow formation at 6 week & $0.0 \pm 0.0$ & $0.6 \pm 0.6$ & $1.0 \pm 0.0$ & 14.828 & 0.000 \\
\hline $\begin{array}{l}\text { SD: Standard deviation; } F \text { value: One-way ANOI } \\
\text { significance at } p<0.05 \text {. }\end{array}$ & lue: Pearson & quare test; & (percentage & fect dian & Statistica \\
\hline
\end{tabular}

\begin{tabular}{|c|c|c|c|}
\hline \multicolumn{4}{|c|}{ TABLE II } \\
\hline Variables & Groups & Mean difference & $p$ \\
\hline \multirow{3}{*}{ Load-to-failure (Newton) } & $1 / 2$ & -3.850 & 0.004 \\
\hline & $1 / 3$ & -3.650 & 0.004 \\
\hline & $2 / 3$ & 0.200 & 0.977 \\
\hline \multirow{3}{*}{ New bone formation at 4 week } & $1 / 2$ & -5.000 & 0.793 \\
\hline & $1 / 3$ & -26.333 & 0.008 \\
\hline & $2 / 3$ & -21.333 & 0.030 \\
\hline \multirow{3}{*}{ Bone marrow formation at 4 week } & $1 / 2$ & -0.400 & 0.354 \\
\hline & $1 / 3$ & -0.667 & 0.065 \\
\hline & $2 / 3$ & -0.267 & 0.591 \\
\hline \multirow{3}{*}{ New bone formation at 6 week } & $1 / 2$ & -26.000 & 0.012 \\
\hline & $1 / 3$ & -50.666 & 0.000 \\
\hline & $2 / 3$ & -24.667 & 0.013 \\
\hline \multirow{3}{*}{ Bone marrow formation at 6 week } & $1 / 2$ & -0.600 & 0.021 \\
\hline & $1 / 3$ & -1.000 & $<0.001$ \\
\hline & $2 / 3$ & -0.400 & 0.113 \\
\hline
\end{tabular}




\begin{tabular}{|c|c|c|c|}
\hline & $\begin{array}{c}\text { TABLE III } \\
\text { Changes in new bone formation between Weeks } 4 \text { an }\end{array}$ & & \\
\hline & Variables & $\mathrm{t}$ & $p$ \\
\hline Group 2 & New bone formation at 4 week/New bone formation at 6 week & -2.828 & 0.047 \\
\hline Group 3 & New bone formation at 4 week/New bone formation at 6 week & -7.000 & 0.001 \\
\hline
\end{tabular}
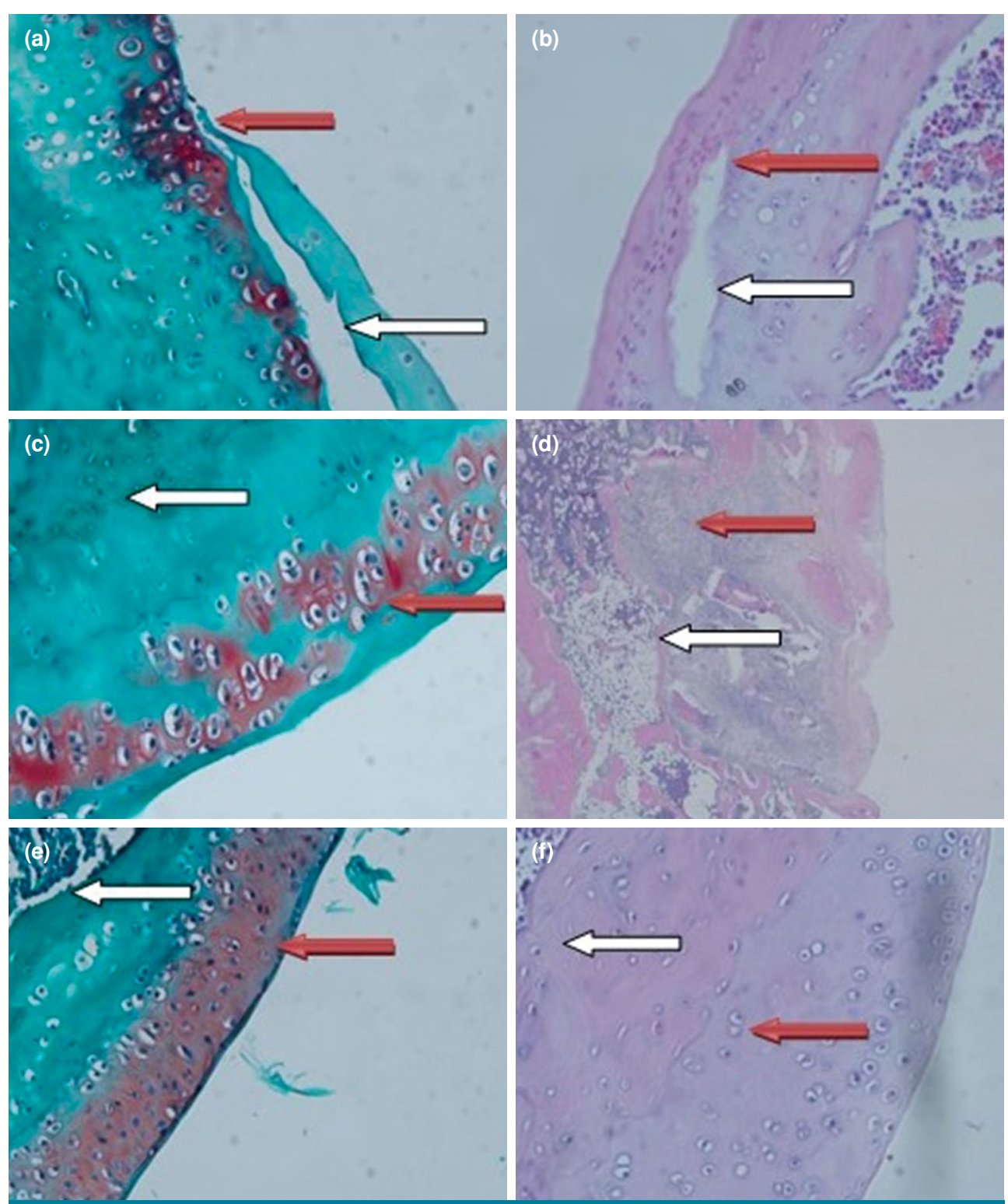

FIGURE 6. Histological examination of bone defects under H-E and trichrome staining. (a) (Group 1) Trichrome staining to show limited new bone formation (osteoblasts: red arrow, non-occluded gap margin: white arrow) (Trichrome staining, $\times 20$ ) (b) (Group 1) H-E staining to show limited new bone formation (osteoblasts: red arrow, non-occluded gap margin: white arrow) $(\mathrm{H}$-E staining, $\times 20)$ (c) (Group 2) Trichrome staining to show limited new bone formation (osteoblasts: red arrow, newly formed bone marrow: white arrow) (Trichrome staining, $\times 20$ ) (d) (Group 2) H-E staining to show limited new bone formation (osteoblasts: red arrow, newly formed bone marrow: white arrow) (H-E staining, $\times 20)(e)(G r o u p 3)$ Trichrome staining to show new bone formation (osteoblasts: red arrow, non-occluded gap margin: white arrow) (Trichrome staining, $\times 20)(f)(G r o u p ~ 1): ~ H-E$ staining to show new bone formation (osteoblasts: red arrow, non-occluded gap margin: white arrow) (H-E staining, $\times 40)$.

H-E: Hematoxylin-eosin. 
PRP applied group) showed a statistically significant amount of early new bone formation compared to Groups 1 and 2 ( $p=0.008$ and $p=0.03$, respectively). However, this difference was significant between Groups 1 and 2 only at six weeks (Table II).

In all periosteum preserved groups (Group 2 and Group 3), bone marrow formation was statistically significant at six weeks compared to Group $1(\mathrm{p}=0.021$ and $p=0.001$ respectively) (Figure 6). Although Group 3 had a higher value of bone marrow formation in the defective area at six weeks, there was no statistically significant difference between Group 2 and Group 3 $(\mathrm{p}=0.113)$ (Table II).

In biomechanical analysis, periosteum preserved groups (Group 2 and Group 3) had statistically superior results compared to Group $1(\mathrm{p}=0.004)$. When Group 2 and Group 3 were compared, there were almost similar results in terms of the bone strength (load-to-failure/Newton) ( $\mathrm{p}=0.977)$ (Table II).

We also compared changes in the new bone formation quantity in Groups 2 and 3 between four and six weeks. There was a statistically significant difference between four and six weeks for both groups. Although the increment at six weeks was evident in PRP applied group $(\mathrm{p}<0.001)$, it was not superior to Group 2 ( $\mathrm{p}=0.047)$ (Table III).

\section{DISCUSSION}

In the current study, we demonstrated that, although we aimed to stimulate periosteal osteogenesis, newly formed bone had a similar strength, irrespective of the PRP application. ${ }^{[19]}$ In periosteum excised bone defect model (Group 1), new bone and marrow formation were slower and weaker compared to periosteum intact ones (Groups 2 and 3). To the best of our knowledge, our study is the first to investigate the PRP effect on periosteum in a bone defect model both histologically and biomechanically.

Consistent with our findings, since Gustilo et al. ${ }^{[20]}$ proved in 1984, severe soft tissue loss with periosteal detachment and compromised vascularity are major factors in delayed fracture healing. Periosteal tissue has been searched for many years to determine its major role in the healing cascade of fractures and bone defects. ${ }^{[5,21]}$ Open fractures, particularly associated with periosteal stripping and high-energy fracture patterns caused by direct trauma, may result in delayed union or nonunions. ${ }^{[20]}$ In our study, we also proved delayed bone healing in periosteum excised group histologically and biomechanically.
Under proper mechanical and chemical stimulation such as trauma, infections and certain tumor types, periosteal tissue has a large capacity to induce callus tissue formation and osteogenesis. ${ }^{[3]}$ One of the two major layers of periosteum, which is called cambium layer, is the major source for osteogenic and chondrogenic precursor cells. ${ }^{[4]}$ Proliferation and differentiation of these cells under proper stimulation is one of the actual concerns in delayed or defective bone healing. ${ }^{[3]}$ Stimulation of periosteum via inflammatory cytokines, growth factors and mechanical signals is the main mechanism to induce osteogenesis. ${ }^{[21]}$ Differentiation of progenitor cells located within the cambium layer into osteoblastic cell lineage improves early phase of fracture healing cascade. ${ }^{[4]}$ Many studies have been conducted to improve periosteal osteogenesis mechanically and biochemically..$^{[22,23]}$ The main signaling pathway in the osteogenic differentiation of periosteal cells include growth factors such as TGF, BMP, IGF-1, and Wnt/b-catenin. ${ }^{[2]}$ Simman et al. ${ }^{[25]}$ showed the therapeutic role of growth factors derived from PRP on long bone fracture healing via inducing periosteum. In our study, we searched to increase osteogenic potential of periosteum under growth factor influence. We found that PRP applied group in which periosteum was replaced had a significantly better new bone formation, compared to the other groups. Increased periosteal osteogenicity seems to depend on growth factors such as PDGF, VEGF, IGF-1, IGF-2, and TGF- $\beta$ supplied by PRP application, as recent studies have demonstrated. ${ }^{[26,27]}$ Yamamiya et al. ${ }^{[7]}$ confirmed the increased regenerative capacity of periosteum in bone defects clinically and radiologically under influence of PRP. They used PRP as a source for growth factors to induce osteoprogenitor cells. Most recently, Xie et al. ${ }^{[28]}$ applied PRP with autogenous bone particles on a rabbit bone defect model and detected increased growth factor concentrations and cell proliferation in the regenerated bone tissue. Halpern et al. ${ }^{[29]}$ also examined tissue healing effects of PRP in musculoskeletal pathologies. The PRP application created an environment with growth factors which induced cell proliferation and migration, angiogenesis, and matrix synthesis in injured tissue. In another study focusing on fracture healing, regenerative effects of PRP were confirmed histologically and biomechanically. ${ }^{[25]}$ In our study, we also found similar results in bone defect healing via PRP induction histologically and biomechanically. Our results support the increased osteogenicity of periosteum with revascularization resulting in bone marrow regeneration. 
In contrast, Reynders et al. ${ }^{[30]}$ showed decreased healing in soft tissue defective fracture model, although periosteum was replaced. They associated decreased osteogenic capacity of periosteum with the lack of growth factors and impaired revascularization of the periosteum. Osteogenic capacity of periosteal tissue with damaged vascularity and soft tissue coverage would result in delayed healing or nonunions in fractures. ${ }^{[31]}$

On the other hand, only PRP application in a periosteum defective model seems to be ineffective. Plachokova et al. ${ }^{[32]}$ applied PRP in a periosteum defective fracture model and found insufficient fracture healing without any intact periosteum.

In our study, although PRP induced periosteal osteogenic capacity, we were unable to confirm it biomechanically. When we compared PRP effect on periosteum biomechanically, in both groups with an intact periosteum, there were similar results in terms of the load-to-failure (Newton). It seems that histologically significant new bone and bone marrow formation in PRP applied group did not add an expected amount of strength to defective bone. Although PRP includes many growth factors such as VEGF, PDGF, IGF-1, IGF-2, and TGF- $\beta$, the lack of BMP seems to explain these biomechanical results. ${ }^{[27]}$ The BMP is the most potent osteoinductive mediator in fracture healing and also plays a major role in the strength of newly formed bone. As reported by Cook, ${ }^{[33]}$ BMP accelerates fracture healing and can be used as substitute in even nonunions. Sarkar et al. ${ }^{[27]}$ also found no effect of PRP on bone formation in critical-size defect biomechanically. They eventually recommended to induce bone regeneration by autologous grafts or osteoinductive growth factors in greater bone defects. In the present study, although we aimed to stimulate periosteal osteogenesis, newly formed bone had a similar strength, irrespective of the PRP application. A more condensed application of growth factors to mimic the environment of early phase of fracture healing may strengthen newly formed bone in greater amounts. Based on our findings, we suggest that application of PRP in soft tissue damaged fractures may improve osteogenesis of periosteal progenitor cells which may decrease nonunion rates and even infections. Early phase of fracture healing may be accelerated under proper growth factor stimulation. Nonetheless, we need further studies to evaluate the PRP effect on osteogenesis and treatment of infective nonunions, as well.

There are several limitations to this study. New bone formation could be assessed by more sophisticated methods such as micro-computerized tomography. In addition, the PRP was applied for once on the first day of experiment. Repeated doses of PRP may have improved the effect on periosteal osteogenesis. Finally, we analyzed mechanical durability only at six weeks. Early testing of the specimens and comparison of early and late results may give us more information about early PRP effect on bone healing.

In conclusion, periosteum has a major role in fracture healing when induced by surrounding soft tissue and mediators. The PRP-derived growth factors may induce periosteal osteogenesis in certain cases. Although new bone formation was significant histologically in this study, biomechanically more durable fracture healing and more specific osteoprogenitor mediators are needed.

\section{Declaration of conflicting interests}

The authors declared no conflicts of interest with respect to the authorship and/or publication of this article.

\section{Funding}

The authors received no financial support for the research and/or authorship of this article.

\section{REFERENCES}

1. Li N, Song J, Zhu G, Li X, Liu L, Shi X, et al. Periosteum tissue engineering-a review. Biomater Sci 2016;4:1554-61.

2. You TM, Choi BH, Li J, Jung JH, Lee HJ, Lee $\mathrm{SH}$, et al. The effect of platelet-rich plasma on bone healing around implants placed in bone defects treated with Bio-Oss: A pilot study in the dog tibia. Oral Surg Oral Med Oral Pathol Oral Radiol Endod 2007;103:e8-12.

3. Simon TM, Van Sickle DC, Kunishima DH, Jackson DW. Cambium cell stimulation from surgical release of the periosteum. J Orthop Res 2003;21:470-80.

4. Chang H, Knothe Tate ML. Concise review: The periosteum: Tapping into a reservoir of clinically useful progenitor cells. Stem Cells Transl Med 2012;1:480-91.

5. Marsell R, Einhorn TA. The biology of fracture healing. Injury 2011;42:551-5.

6. Kanou M, Ueno T, Kagawa T, Fujii T, Sakata Y, Ishida N, et al. Osteogenic potential of primed periosteum graft in the rat calvarial model. Ann Plast Surg 2005;54:71-8.

7. Yamamiya K, Okuda K, Kawase T, Hata K, Wolff LF, Yoshie H. Tissue-engineered cultured periosteum used with platelet-rich plasma and hydroxyapatite in treating human osseous defects. J Periodontol 2008;79:811-8.

8. Saulacic N, Schaller B, Iizuka T, Buser D, Hug C, Bosshardt DD. Analysis of new bone formation induced by periosteal distraction in a rat calvarium model. Clin Implant Dent Relat Res 2013;15:283-91.

9. Çirci E, Akman YE, Şükür E, Bozkurt ER, Tüzüner T, Öztürkmen Y. Impact of platelet-rich plasma injection timing on healing of Achilles tendon injury in a rat model. Acta Orthop Traumatol Turc 2016;50:366-72.

10. Dallaudière $B$, Lempicki $M$, Pesquer L, Louedec L, Preux PM, Meyer P, et al. Efficacy of intra-tendinous 
injection of platelet-rich plasma in treating tendinosis: Comprehensive assessment of a rat model. Eur Radiol 2013;23:2830-7.

11. Meheux CJ, McCulloch PC, Lintner DM, Varner KE, Harris JD. Efficacy of intra-articular platelet-rich plasma injections in knee osteoarthritis: A systematic review. Arthroscopy 2016;32:495-505.

12. Scott A, LaPrade RF, Harmon KG, Filardo G, Kon E, Della Villa $S$, et al. Platelet-rich plasma for patellar tendinopathy: A randomized controlled trial of leukocyte-rich PRP or leukocyte-poor PRP versus saline. Am J Sports Med 2019;47:1654-61.

13. Görmeli G, Görmeli CA, Ataoglu B, Çolak C, Aslantürk $\mathrm{O}$, Ertem K. Multiple PRP injections are more effective than single injections and hyaluronic acid in knees with early osteoarthritis: A randomized, double-blind, placebocontrolled trial. Knee Surg Sports Traumatol Arthrosc 2017;25:958-65.

14. Okuda K, Yamamiya K, Kawase T, Mizuno H, Ueda M, Yoshie $\mathrm{H}$. Treatment of human infrabony periodontal defects by grafting human cultured periosteum sheets combined with platelet-rich plasma and porous hydroxyapatite granules: Case series. J Int Acad Periodontol 2009;11:206-13.

15. Metzler P, von Wilmowsky C, Zimmermann R, Wiltfang J, Schlegel KA. The effect of current used bone substitution materials and platelet-rich plasma on periosteal cells by ectopic site implantation: An in-vivo pilot study. J Craniomaxillofac Surg 2012;40:409-15.

16. Balmayor ER, Geiger JP, Aneja MK, Berezhanskyy T, Utzinger M, Mykhaylyk $\mathrm{O}$, et al. Chemically modified RNA induces osteogenesis of stem cells and human tissue explants as well as accelerates bone healing in rats. Biomaterials 2016;87:131-46.

17. Kido HW, Bossini PS, Tim CR, Parizotto NA, da Cunha AF, Malavazi I, et al. Evaluation of the bone healing process in an experimental tibial bone defect model in ovariectomized rats. Aging Clin Exp Res 2014;26:473-81.

18. Kasten P, Vogel J, Geiger F, Niemeyer P, Luginbühl R, Szalay $K$. The effect of platelet-rich plasma on healing in criticalsize long-bone defects. Biomaterials 2008;29:3983-92.

19. Atik OŞ. Is there something new and interesting in my article? Eklem Hastalik Cerrahisi 2019;30:69.

20. Gustilo RB, Mendoza RM, Williams DN. Problems in the management of type III (severe) open fractures: A new classification of type III open fractures. J Trauma 1984;24:742-6.
21. Colnot C, Zhang X, Knothe Tate ML. Current insights on the regenerative potential of the periosteum: Molecular, cellular, and endogenous engineering approaches. J Orthop Res 2012;30:1869-78.

22. Batista JM, Nakagaki WR, Soares EA, Camilli JA. Effects of low-intensity pulsed ultrasound exposure on rats tibia periosteum. An Acad Bras Cienc 2020;92:e20180903.

23. Oktaş B, Orhan Z, Erbil B, Değirmenci E, Ustündağ N. Effect of extracorporeal shock wave therapy on fracture healing in rat femural fractures with intact and excised periosteum. Eklem Hastalik Cerrahisi 2014;25:158-62.

24. Wang T, Zhang X, Bikle DD. Osteogenic differentiation of periosteal cells during fracture healing. J Cell Physiol 2017;232:913-21.

25. Simman R, Hoffmann A, Bohinc RJ, Peterson WC, Russ AJ. Role of platelet-rich plasma in acceleration of bone fracture healing. Ann Plast Surg 2008;61:337-44.

26. Marx RE, Carlson ER, Eichstaedt RM, Schimmele SR, Strauss JE, Georgeff KR. Platelet-rich plasma: Growth factor enhancement for bone grafts. Oral Surg Oral Med Oral Pathol Oral Radiol Endod 1998;85:638-46.

27. Sarkar MR, Augat P, Shefelbine SJ, Schorlemmer S, HuberLang M, Claes L, et al. Bone formation in a long bone defect model using a platelet-rich plasma-loaded collagen scaffold. Biomaterials 2006;27:1817-23.

28. Xie H, Cao L, Ye L, Du J, Shan G, Hu J, et al. Autogenous bone particles combined with platelet-rich plasma can stimulate bone regeneration in rabbits. Exp Ther Med 2020;20:279.

29. Halpern BC, Chaudhury S, Rodeo SA. The role of plateletrich plasma in inducing musculoskeletal tissue healing. HSS J 2012;8:137-45.

30. Reynders P, Becker JH, Broos P. Osteogenic ability of free periosteal autografts in tibial fractures with severe soft tissue damage: An experimental study. J Orthop Trauma 1999;13:121-8.

31. Hattori K, Yoshikawa T, Takakura Y, Aoki H, Sonobe M, Tomita N. Bio-artificial periosteum for severe open fracture--an experimental study of osteogenic cell/collagen sponge composite as a bio-artificial periosteum. Biomed Mater Eng 2005;15:127-36.

32. Plachokova AS, van den Dolder J, Stoelinga PJ, Jansen JA. The bone regenerative effect of platelet-rich plasma in combination with an osteoconductive material in rat cranial defects. Clin Oral Implants Res 2006;17:305-11.

33. Cook SD. Preclinical and clinical evaluation of osteogenic protein-1 (BMP-7) in bony sites. Orthopedics 1999;22:669-71. 